\title{
Macro and Non-macro Determinants of Korean Tourism Stock Performance: A Quantile Regression Approach
}

\author{
Ji-Hong JEON*
}

Received: October 26, 2019 Revised: January 30, 2020 Accepted: February 06, 2020.

\begin{abstract}
The study aims to investigate a close relation between macro and non-macro variables on stock performance of tourism companies in Korea. The sample used in this study includes monthly data from January 2001 to December 2018. The stock price index of the tourism companies as a dependent variable are obtained from Sejoong, HanaTour, and RedcapTour as three leading Korean tourism companies that have been listed on the Korea Stock Exchange. This study assesses the tourism stock performance using the quantile regression approach. This study also investigates whether global crisis events as the Iraq War and the global financial crisis as non-macro variables have a significant effect on the stock performance of tourism companies in Korea. The results show that the oil prices, exchange rate and industrial production have negative coefficients on stock prices of tourism companies, while the effects of tourist expenditure and consumer price index are positive and significant. We estimate the result of quantile regression that non-macro determinants have statistically a significant and negative effect on tourism stock performance because the global crisis could threaten traveler's safety and economy. Overall, empirical results suggest that the effects of macro and non-macro variables are statistically asymmetric and highly related to tourism stock performance.
\end{abstract}

Keywords: Tourism, Stock Performance, Macro and non-macro, Quantile Regression, Korea

JEL Classification Code: C32, L83, N10

\section{Introduction}

Many previous papers provide a considerable amount of research for tourism stock market. The existing tourism literature has been focused the relationship between tourism stock returns and macro-economic variables (Chang \& Lee, 2017; Demir, Alici, \& Lau, 2017). Our empirical evidence establishes a connection between macro and non-macro variables on tourism stock market in Korea by using the quantile regression $(\mathrm{QR})$ for the main estimation.

Previous literature has shown the effect of non-macro variables as well as macro variables on travel stock price. Chen, Kim, and Kim (2005) estimated the relationship of macro and non-macro variables on Taiwan's hotel stock. This paper demonstrates the relationship between macro

${ }^{*}$ First Author and Corresponding Author. Adjunct Professor, School of Business, Hanyang University, Korea.

Tel: +82-2-2220-2435, Email: cellc@hanyang.ac.kr

(c) Copyright: The Author(s)

This is an Open Access article distributed under the terms of the Creative Commons Attribution NonCommercial License (https://creativecommons.org/licenses/by-nc/4.0/) which permits unrestricted noncommercial use, distribution, and reproduction in any medium, provided the original work is properly cited. and non-macro variables on stock performance of tourism companies in Korea and forecasts the future tourism economy of Korea through the stock price of tourism companies. In detail, this study is to explore how the stock price of Korean tourism companies, which represent Korea's travel industry, is influenced by macro and nonmacro explanatory variables.

An empirical analysis is conducted using oil price, exchange rate, tourism expenditure, consumer price index (CPI), and Industrial production (IP) as the main macro explanatory factors affecting the stock price. In particular, two global events were used as a dummy variable to examine the influence of the Iraq War that occurred in early 2003, which affected the stock price and traveler demand of the tourism, and global financial which it substantially affected the earnings of tourism companies and tourism stock market in Korea. Therefore, the non-macro variables, the Iraq War and the global financial crisis, are the key determinants for assessing the effects on stock performance of tourism companies in Korea.

Our paper reveals the first evidence of the effects of macro and non-macro explanatory variables on the stock 
performance of the tourism companies in Korea using a QR approach. For the top two purposes of this paper, first, we investigate how macro variables affects the tourism stock market in Korea dividing into three phases that correspond a bearish, normal, and bullish markets using QR (Nusair and Olson (2019). Second, the study testifies to the impact of travel crisis such as the terrorist attack and disease on stock markets in Korea. We investigate the effect of macro and non-macro variables on tourism stock performance in Korea.

\section{Literature Review}

The tourism studies have been commonly researched the relationship between tourism and macro-economic (Lee \& Syah, 2018; Wong \& Song, 2006) as well as non-economic variables such as the terror and consumer psychology. (Chen, 2007; Cheng \& Jiang, 2017; Lee \& Kwag, 2013; Park \& Park, 2019; Singal, 2012; Yespayev, 2014; Yu, Lee, \& Kim, 2014; Zhang \& Lee, 2016).

Scholars have used the stock price in a number of prior empirical studies on tourism, but these studies have mainly focused on macroeconomic issues for the stock performance of tourism companies. Firstly, the macroeconomic variables used in this study, the exchange rate and the oil prices, have been described as for major factors affecting the stock price. In detail, stock prices are tied closely to exchange rate by the portfolio balance effect (Tsai, 2012). When the foreign capital flow out (in) the stock markets, there is depreciation (appreciation) of currencies. Stock prices are related to the fluctuation of oil price. If oil prices rise, production costs may increase, which may lead to a decline in stock prices (Broadstock, Cao, \& Zhang, 2012; Nandha \& Faff, 2008).

The CPI can positively or negatively affect the stock price. The empirical analysis of the relationship between stock prices and CPI using 10 European countries, including Germany, the UK and France, shows that stock prices are positively related to CPI (Asprem, 1989). IP is negatively related to the analysis of the hospitality industry stock (Singal, 2012). Errunza and Hogan (1998) also find that the volatility of European stock prices is negatively related to the IP for Germany and France by using the vector autoregressive (VAR) model. There are key determinants of tourism performance, such as capital, expenditures, revenues, and external economic factors ( $\mathrm{Li}$, Jin, \& Shi, 2018).

Previous literature has shown the effect of non-macro variables as well as macro variables on travel stock price. In particular, we investigate the effect of macro and nonmacro variables on tourism stock performance in Korea. The rest contents are organized as follows. We describe the empirical data and methodology used to estimate this study. After analyzing results, finally we provide concluding remarks.

\section{Research Data and Empirical Model}

\subsection{Research Data}

The sample used in this study includes monthly data from January 2001 to December 2018. The stock price index of the tourism companies as a dependent variable are obtained from Sejoong, HanaTour, and RedcapTour as three leading Korean tourism companies that have been listed on the Korea Exchange (KRX). In equation (1), it was measured by the market-capitalization weighted index on the basis which the index value at the end of December 2000 is equal to 100 .

$$
S P_{t}=\frac{T M C_{t}}{T M C_{o}} \times 100
$$

where $S P_{t}$ is the stock price index of tourism companies in the specific month (t), it is calculated by $T M C_{t}$ and $T M C_{0}$ as the total market capitalization (TMC) of the stock price on all tourism companies at the base point.

In this study, there are macro and non-macro explanatory factors of tourism stock performance in Korea. We select the macro and non-macro variables on tourism stock performance in Korea according to the research by Chen (2007) and Chen, Kim, and Kim (2005) that they investigated an immense influence of macro and non-macro variables on stock returns in China and Taiwan hotels respectively. The macro explanatory variables are the Dubai price of oil (OP) which obtained from World Bank as the oil price because the share of Dubai oil has taken over 70 per cent of the total oil consumption used in Korea, exchange rate (EX) defined as the Korean won against the US dollar (KRW/USD), Korean tourist expenditure for outbound tourism, consumer price index (CPI) and industrial production (IP) in Korea.

We used the Dubai oil price as the oil price because the share of Dubai oil has taken over 70 per cent of the total oil consumption used in Korea. We used non-macro explanatory variables which are dummy variables related the Iraq War and the global financial crisis threaten traveler's safety and economy. Because the global crisis events seriously can weaken the returns of Korean outbound tourism stocks similar to studies reported in Chen and Kim (2010) which the SARS (Severe Acute Respiratory Syndrome) epidemic struct China in 2003 reduced the returns of hotel stocks and Korea outbound travel demand. In particular, the dummy of the Iraq War, IRAQ dummy, has 
great implications for us because the Iraq War in 2003 overlapped with the outbreak period of SARS. Table 1 shows the macro variables and their definitions and sources.

Table 1: Description of variables

\begin{tabular}{|c|c|c|}
\hline Variable & Description & Database \\
\hline TSI (DV) & Tourism stock index & Yahoo Finance \\
\hline OP & Oil price & World Bank \\
\hline EX & $\begin{array}{c}\text { Exchange Rate } \\
\text { (KRW/USD) }\end{array}$ & Bank of Korea (BOK) \\
\hline TE & $\begin{array}{c}\text { Tourist expenditure } \\
\text { (USD million) }\end{array}$ & $\begin{array}{c}\text { Korea Tourism Organization } \\
\text { (KTO) }\end{array}$ \\
\hline CPI & Consumer price index & Statistics Korea (KOSTAT) \\
\hline IP & Industrial production & Statistics Korea (KOSTAT) \\
\hline
\end{tabular}

Notes: DV means dependent variable.

Table 2 presents the summary statistics of tourism stock and five macro variables. In addition to macro factors, two non-macro variables for the global crisis events were included to estimate how these variations affect the stock performance.

Table 2: Summary statistics of data $(\mathrm{N}=216)$

\begin{tabular}{|c|r|r|r|r|r|}
\hline Variable & \multicolumn{1}{c|}{ Mean } & \multicolumn{1}{c|}{ Median } & \multicolumn{1}{c|}{ Min } & \multicolumn{1}{c|}{ Max } & \multicolumn{1}{c|}{ SD } \\
\hline TSI (DV) & 522.38 & 508.84 & 59.57 & $1,473.28$ & 325.92 \\
\hline OP & 63.94 & 58.93 & 17.53 & 131.23 & 29.84 \\
\hline EX & $1,123.63$ & $1,125.35$ & 907.40 & $1,516.40$ & 108.74 \\
\hline TE & $1,325.76$ & $1,265.95$ & 434.70 & $2,774.50$ & 528.14 \\
\hline CPI & 88.57 & 89.62 & 68.10 & 105.65 & 11.40 \\
\hline IP & 74.00 & 65.40 & 36.90 & 15.00 & 28.95 \\
\hline
\end{tabular}

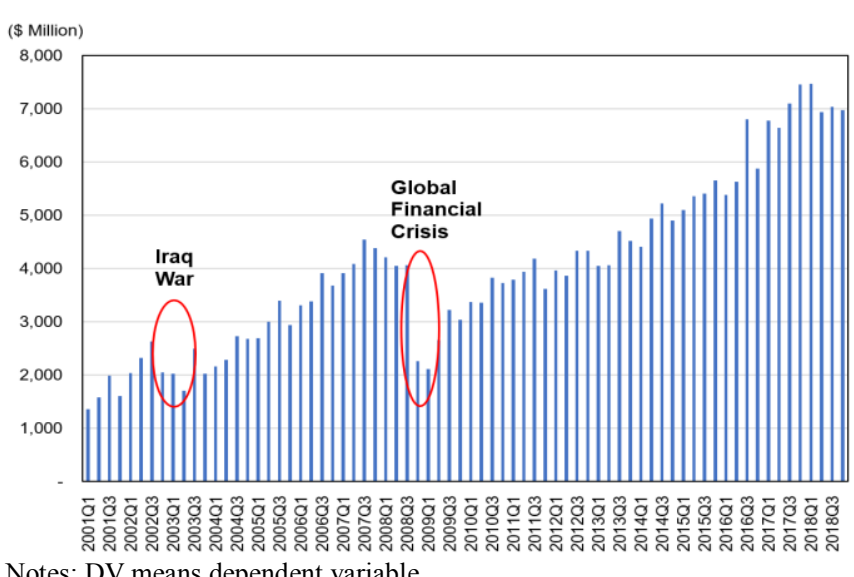

Notes: DV means dependent variable.

Figure 1: Quarterly international tourist expenditure in Korea (2001-2018)

Figure 1 shows the expenditure of quarterly outbound travelers departing from Korea. In particular, the tourist expenditure decreased sharply due to the uncertainty of safe travel and a depressed income of outbound traveler when the Iraq War and global financial crisis happened.

\subsection{Empirical Model}

The QR proposed by Koenker and Bassett (1978), an alternative to the traditional regression analysis, is evaluated as a robust model to outliers and heavy-tailed distributions of explanatory variables, unlike the existing regression analysis that it does not explain the entire conditional distributional properties of the dependent variable. Therefore, the strong advantage of using QR analysis is that it describes the explanatory effects of variables at different quantiles. The regression analysis is shown as equation (2).

There is a model for obtaining the statistics of ordinary least squares (OLS) regression. To estimate whether nonmacro factors affect tourism stock index (TSI), we incorporated IRAQ $Q_{\text {dummy }}$ and $G F C_{\text {dummy }}$ as non-macro variables into this model along with macro variables which are $\ln (O P), \ln (E X), \ln (C P), \ln (I P)$, and $\ln (T E)$.

$$
\begin{aligned}
\ln \left(T S I_{t}\right)=\alpha+ & \beta_{1} \ln \left(O P_{t}\right)+\beta_{2} \ln \left(E X_{t}\right)+\beta_{3} \ln \left(C P_{t}\right) \\
& +\beta_{4} \ln \left(I P_{t}\right)+\beta_{5} \ln \left(T E_{t}\right) \\
& +\beta_{6} I R A Q_{\text {dummy }}+\beta_{7} G F C_{\text {dummy }} \\
& +\varepsilon_{t}
\end{aligned}
$$

where intercept $\alpha$ and slope coefficients $\beta 1 \sim \beta 7$ are estimated parameters and $\varepsilon_{\mathrm{t}}$ is the error term. IRAQ dummy for Iraq War (1 if 2003:3-2003:6, 0 elsewhere) and $G F C_{\text {dummy }}$ for the global financial crisis (1 if 2008:9-2008:12, 0 elsewhere) are dummy variables on the unity value upon a non-macro events and zero if not, and $t$ is the time indicating the related month.

We use the quantile regression based on equation (3) to examine the influence of financial factors on stock performance of tourism companies in Korea. The quantile estimator is gained by solving the following optimization problem:

$$
\min _{b \in R^{K}}\left[\sum_{i \in\left\{i: y_{i} \geq x_{i} \beta\right\}} \theta\left|y_{i}-x_{i} \beta\right|+\sum_{i \in\left\{i: y_{i}<x_{i} \beta\right\}} 1-\theta\left|y_{i}-x_{i} \beta\right|\right]
$$

for the $\theta_{\text {th }}$ quantile $(0<\theta<1)$, where $\mathrm{y}_{\mathrm{i}}$ indicates the stock performance of tourism companies as the dependent variable and $\chi_{\mathrm{i}}$ denotes a $\mathrm{k}$ by 1 vector of explanatory variables.

In this study, we follow previous literature by You, Guo, Zhu, and Tang (2017) who they divide into three phases to employ a QR approach in the stock market: lower quantiles $(\tau=0.10,0.25)$ are equivalent to a bearish market that means a period of falling stock prices with pessimism, medium (intermediate) quantile $(\tau=0.50)$ is equivalent to 
the normal market and upper (higher) quantiles $(\tau=0.75$, 0.90 ) are equivalent to a bullish market that means a period of rising stock prices with optimism. We choose five quantiles $(\tau=0.10,0.25,0.50,0.75,0.90)$ as the same pattern by Marrocu, Paci, and Zara (2015), and Lv and Xu (2017) for an estimation of QR approach.

\section{Results}

Table 3 shows the empirical results for comparison between OLS regression and the QR with five quantiles for the stock performance of tourism companies for the macro and non-macro explanatory variables. Particularly, in QR, the pseudo R-squared values show that the lower quantiles $(\tau=0.10,0.25)$ in bearish market have greater explanatory power than the upper quantiles $(\tau=0.75,0.90)$ in a bullish market.

Firstly, the results of OLS regression show significantly that exchange rate, CPI, and IRAQ dummy are the main performance determinants of the stock performance of tourism companies. In particular, the coefficient of the exchange rate is significantly negative. Additionally, the result of OLS regression shows significantly a positive linkage between tourism stock and CPI. The coefficient of

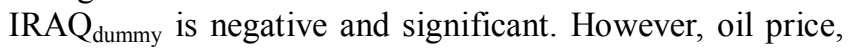
tourist expenditure, IP, and $\mathrm{GFC}_{\text {dummy }}$ had no significant effect on tourism stock in OLS model.

In this paper, the relationship between tourism stock and oil price is reexamined using QR. According to the results of QR approach, oil price has significantly a negative relationship with the travel agency stock performance at the medium quantile (50th) and upper (75th and 90th) quantiles. That is, oil price affects the stock performance of tourism companies in both normal and bullish markets. Similarly, the oil price changes affect negatively stock returns to Asian countries such as Japan, Korea, and Thailand in Cunado and Perezde Gracia (2005) and Hamilton (2011).

The result of the QR approach for the exchange rate has a significant and negative relationship with tourism stock at all quantiles to support the portfolio balance approach. In detail, Liang, Lin, and Hsu (2013) and Wong (2017) provide the evidence to indicate a negative linkage between the stock and exchange rate in Asian countries such as Malaysia, Japan, Korea. Regarding the statistical properties of the exchange rate, the appreciation of Korean Won/US dollar exchange rate is related to the rise of tourism stock. Given the definition of the exchange rate Korean won against US dollar, a positive change indicates Korean won depreciation, and a negative change indicates Korean won appreciation.

Furthermore, the evidence supports that the coefficient estimates on tourist expenditure are significantly positive at all quantiles except the 25th quantile. In similar, studies related to the outbound tourism and stock markets by Dragouni, Filis, Gavriilidis, and Santamaria (2016), the increase of the tourism demand is attributed to an increase in the stock market that changes into an increase in public mood.

The CPI has significantly a positive linkage with tourism stock for all quantiles. This result is similar to the empirical estimation in European countries reported by Asprem (1989).

The IP significantly has a negative relationship with tourism stock at the 25th, 50th, 75th, and 90th quantiles. The results are similar to that estimated by Poon and Taylor (1991).

We predict that the IRAQ $Q_{\text {dummy }}$ and $\mathrm{GFC}_{\text {dummy }}$ have the significant coefficient, that is, these variables have a significant influence on stock performance of tourism firms because it has directly related the traveler's safety (Chen et al., 2005; Liu \& Pratt, 2017; Lo \& Lam, 2004). The result indicates that the IRAQ dummy has a negative effect on the tourism stock at the 50th, 75th, and 90th quantiles. That is, we find that tourism stock is deteriorated by the Iraq War outbreak in 2003.

In summary, we can conclude that the exchange rate and CPI are the strongest determinants of stock performance of tourism companies in Korea because the coefficients of exchange rate and the CPI were highly significant in all quantiles. Also, macro explanatory variables mostly pull up more the stock price in the bullish market than in the bearish market. In addition, global crisis events such as the Iraq War and global financial crisis as non-macro explanatory variables play a central role in making these results.

In Figure 2, we graphically depict the estimated impacts of explanatory variables on tourism stock. Also, it shows the trends between the size quantile and coefficients of explanatory variables on tourism stock. The horizontal lines represent OLS estimated impacts of macro and non-macro explanatory variables, while the curves are QR estimated impacts on the $\tau_{\text {th }}$ quantile of tourism stock. That is, each graph shows the estimated QR coefficients and OLS coefficients along with $95 \%$ confidence intervals for the macro and non-macro explanatory variables on the vertical $y$-axis across the whole quantile spectrum of tourism stock distribution for $0 \leq \tau \leq 1$ on the horizontal $\mathrm{x}$-axis which represents the five point estimates over the distribution of each 20 percentile. We find that the QR model has a different picture compared with the OLS model. We plot the intercept for the whole quantile distribution. Figure 2 demonstrates that tourist expenditure and CPI have positive coefficients throughout the distribution, while exchange rate, IP, and IRAQ dummy have negative coefficients across the entire quantile distributions. The pattern of monotonic 
decreases in the responsiveness can be seen for oil price and IRAQ dummy. $_{\text {. }}$

In addition, the results show that a rising oil price causes the tourism stock to decrease. Our results of the coefficient on exchange rate again support the portfolio balance approach by Wong (2017). Therefore, this explains the negative relationship between tourism stock and exchange rate. The coefficient on tourist expenditure is positive mostly at all quantile intervals.

The coefficient on IP is predominantly at most quantiles, stock return quantiles. For the IRAQ $Q_{\text {dummy }}$ dependence has a significant and negative association with tourism stock. Moreover, the $\mathrm{GFC}_{\text {dummy }}$ has a significant and negative relationship with tourism stock for almost all quantiles with the downward trend similar to the IRAQ $\mathrm{Q}_{\text {dummy }}$ dependence due to the fact that the safety is one of the important determinants when outbound tourists make international travel decisions. Therefore, a negative impact of the Iraq War, the SARS outbreak on tourism stock price is expected with the finding of Chen et al. (2005) and Rittichainuwat and Chakraborty (2009).

In Table 4, we document the results of the slope equality test described by Koenker and Bassett (1982). We conduct the Wald test with the following null hypotheses (Ho): $\beta_{0.1}$ $=\beta_{0.9}, \beta_{0.1}=\beta_{0.5}, \beta_{0.5}=\beta_{0.9}, \beta_{0.25}=\beta_{0.75}, \beta_{0.1}=\beta_{0.25}=\beta_{0.50}=$ $\beta_{0.75}=\beta_{0.9}$. We document the F-statistics and p-value in Table 4. For example, the results report that the null hypotheses of equality of the slope coefficients at the 10th and the 90th quantiles were being rejected at the 5\% significance level for oil price, CPI, and IRAQ dummy affected by bearish and bullish stock markets. The evidence would support that the significant coefficient at the 10th quantile is different from that at the 90th quantile. Another important finding is that dummy variable, IRQA $A_{\text {dummy }}$, is rejected the null hypotheses at the 5\% significance level. Furthermore, these results for the overall slope equality test further support our $\mathrm{QR}$ results, suggesting that $\beta_{0.1}=\beta_{0.25}=$ $\beta_{0.50}=\beta_{0.75}=\beta_{0.9}$ are rejected at the $5 \%$ significance level because there are significant differences between the coefficients of macro and non-macro explanatory variables. Therefore, we examine the slope equality test by comparing the estimated coefficients of other quantiles. Although all variables are not rejected the null hypotheses at the 5\% significance level, another important finding is that the results are asymmetrical because estimated slope coefficients for $\beta_{0.1}=\beta_{0.25}=\beta_{0.50}=\beta_{0.75}=\beta_{0.9}$ are rejected at the $5 \%$ significance level for all variables. Overall, we find out the slope of regression varies across the different quantiles. This results document that it is not constant as assumed in OLS.

Table 3: OLS and quantile regression results on the tourism stock index

\begin{tabular}{|c|c|c|c|c|c|c|}
\hline \multirow{3}{*}{ Variables } & \multirow{3}{*}{ OLS } & \multicolumn{5}{|c|}{ Quantile regression } \\
\hline & & \multicolumn{2}{|c|}{ Bearish market } & \multirow{2}{*}{$\begin{array}{c}\text { Normal market } \\
50 \text { th }\end{array}$} & \multicolumn{2}{|c|}{ Bullish market } \\
\hline & & 10th & 25th & & 75th & 90th \\
\hline \multirow{2}{*}{$\ln (\mathrm{OP})$} & -0.034 & 0.071 & 0.041 & $-0.235 * *$ & $-0.371 * * *$ & $-0.287 * * *$ \\
\hline & $(0.100)$ & $(0.096)$ & $(0.106)$ & $(0.112)$ & $(0.122)$ & $(0.078)$ \\
\hline \multirow{2}{*}{$\ln (\mathrm{EX})$} & $-2.508 * * *$ & $-2.235 * * *$ & $-1.338 * *$ & $-2.390 * * *$ & $-3.088 * * *$ & $-2.599 * * *$ \\
\hline & $(0.502)$ & $(0.477)$ & $(0.532)$ & $(0.842)$ & $(0.609)$ & $(0.666)$ \\
\hline \multirow{2}{*}{$\ln (\mathrm{TE})$} & 0.327 & 0.195 & $0.586^{* *}$ & $0.469 * *$ & $0.324 *$ & $0.546^{*}$ \\
\hline & $(0.224)$ & $(0.213)$ & $(0.238)$ & $(0.222)$ & $(0.272)$ & $(0.298)$ \\
\hline \multirow{2}{*}{$\ln (\mathrm{CPI})$} & $4.953 * * *$ & $6.267 * * *$ & $5.334 * * *$ & $6.104 * * *$ & $6.205^{* * *}$ & $4.353^{* * *}$ \\
\hline & $(0.856)$ & $(0.814)$ & $(0.907)$ & $(1.436)$ & $(1.039)$ & $(1.137)$ \\
\hline \multirow{2}{*}{$\ln (\mathrm{IP})$} & -0.222 & -0.294 & $-0.328 * * *$ & $-0.774 * * *$ & $-0.899 * * *$ & $-0.407 * *$ \\
\hline & $(0.276)$ & $(0.262)$ & $(0.908)$ & $(0.166)$ & $(0.335)$ & $(0.176)$ \\
\hline \multirow{2}{*}{ IRAQ dummy $_{\text {d }}$} & $-0.580 * * *$ & -0.063 & -0.108 & $-0.742 * * *$ & $-1.174 * * *$ & $-1.191 * * *$ \\
\hline & $(0.190)$ & $(0.181)$ & $(0.201)$ & $(0.163)$ & $(0.230)$ & $(0.252)$ \\
\hline \multirow{2}{*}{$\mathrm{GFC}_{\text {dummy }}$} & 0.108 & 0.263 & 0.125 & -0.064 & $-0.238 * * *$ & 0.093 \\
\hline & $(0.190)$ & $(0.180)$ & $(0.201)$ & $(0.318)$ & $(0.031)$ & $(0.252)$ \\
\hline \multirow{2}{*}{ Constant } & -2.083 & $-8.602 *$ & $-15.782 * * *$ & $-6.909 * * *$ & 0.921 & 0.386 \\
\hline & (4.989) & $(4.743)$ & $(5.285)$ & (1.817) & $(6.051)$ & $(6.625)$ \\
\hline $\mathrm{R}^{2}$ or Pseudo $\mathrm{R}^{2}$ & 0.840 & 0.707 & 0.706 & 0.597 & 0.523 & 0.498 \\
\hline
\end{tabular}

Notes: Standard errors are in parentheses. $*, * *, * *$ denote significance at the $1 \%, 5 \%$, and $10 \%$ levels. OP, EX, TE, CPI, IP, IRAQdummy, and GFC dummy $_{\text {dum }}$ denote separately oil price, exchange rate, tourist expenditure, consumer price index, industrial production, Iraq War dummy, and global financial crisis dummy 

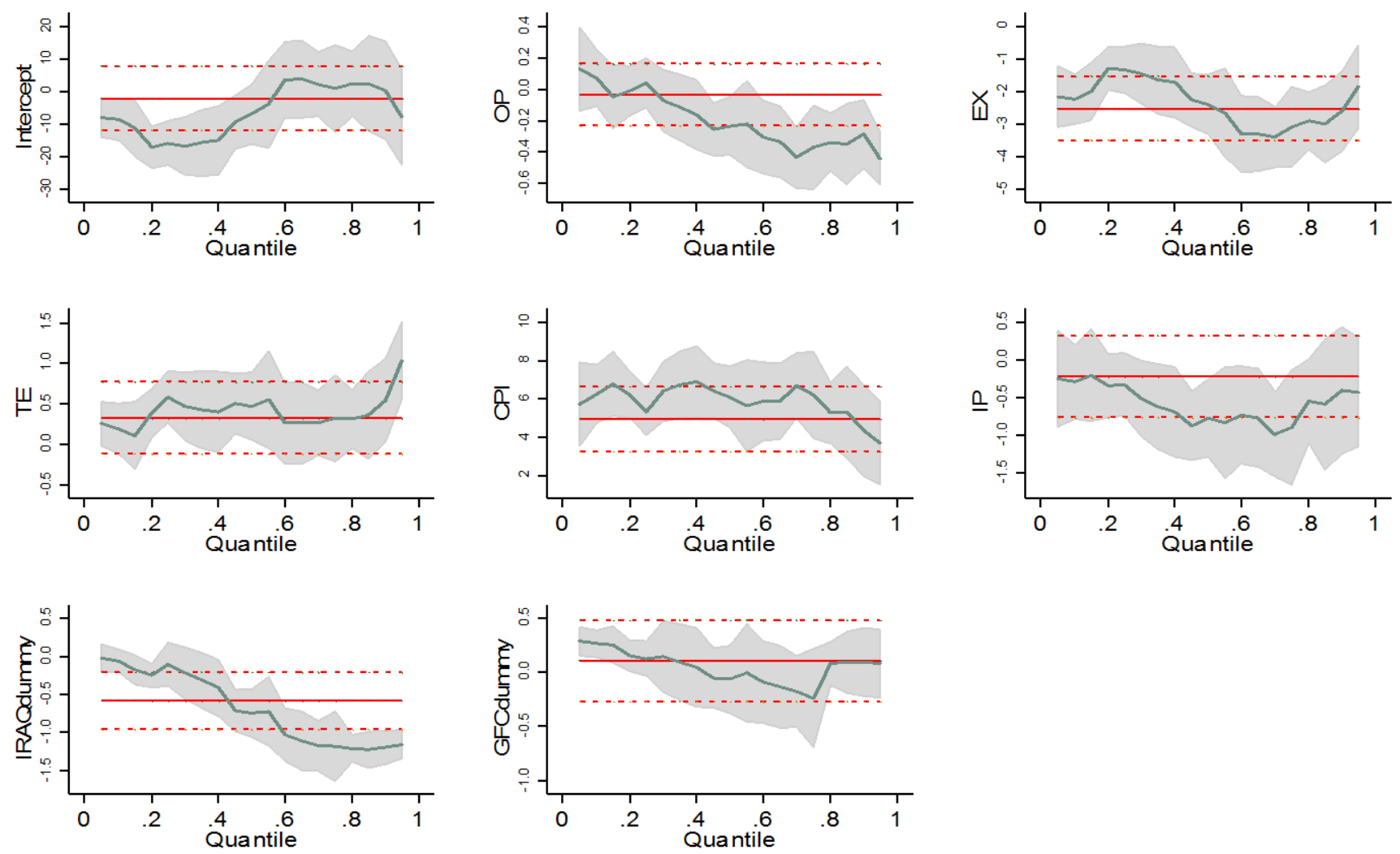

Figure 2: Quantile regression coefficient estimates for the tourism stock index (TSI)

Notes: Solid horizontal line: OLS-coefficient; dashed horizontal lines: corresponding $95.0 \%$ confidence bands. Solid curve: quantile-specific coefficients; shaded curves: corresponding $95.0 \%$ confidence bands. OP, EX, TE, CPI, IP, IRAQdummy, and $\mathrm{GFC}_{\text {dummy }}$ indicate separately oil price, exchange rate, tourist expenditure, consumer price index, industrial production, Iraq War dummy, and global financial crisis dummy.

Table 4: Slope equality test (asymmetric model)

\begin{tabular}{|c|c|c|c|c|c|}
\hline Но & $\boldsymbol{\beta}_{0.1}=\boldsymbol{\beta}_{0.9}$ & $\boldsymbol{\beta}_{0.1}=\boldsymbol{\beta}_{0.5}$ & $\boldsymbol{\beta}_{0.5}=\boldsymbol{\beta}_{0.9}$ & $\boldsymbol{\beta}_{0.25}=\boldsymbol{\beta}_{0.75}$ & $\begin{array}{c}\boldsymbol{\beta}_{0.1}=\boldsymbol{\beta}_{0.25}=\boldsymbol{\beta}_{0.5} \\
=\boldsymbol{\beta}_{0.75}=\boldsymbol{\beta}_{0.9}\end{array}$ \\
\hline \multirow{2}{*}{$\mathrm{OP}$} & 8.55 & 4.72 & 0.12 & 19.52 & 173.26 \\
\hline & $(0.004)$ & $(0.031)$ & $(0.732)$ & $(0.000)$ & $(0.000)$ \\
\hline \multirow{2}{*}{ EX } & 0.08 & 0.03 & 0.07 & 5.27 & 3.92 \\
\hline & $(0.784)$ & $(0.866)$ & $(0.789)$ & $\begin{array}{l}(0.023) \\
\end{array}$ & $\begin{array}{l}(0.004) \\
\end{array}$ \\
\hline \multirow{2}{*}{ TOE } & 0.35 & 0.87 & 0.07 & 0.76 & 2954.9 \\
\hline & $(0.554)$ & $(0.351)$ & $(0.797)$ & $(0.384)$ & $\begin{array}{l}(0.000) \\
\end{array}$ \\
\hline \multirow{2}{*}{ CPI } & 8.92 & 0.04 & 3.66 & 1.40 & 10.09 \\
\hline & $(0.003)$ & $(0.851)$ & $(0.057)$ & $(0.238)$ & $(0.000)$ \\
\hline \multirow{2}{*}{ IP } & 0.06 & 2.44 & 2.37 & 3.89 & 5.73 \\
\hline & $(0.807)$ & $(0.119)$ & $(0.125)$ & $(0.050)$ & $(0.000)$ \\
\hline \multirow{2}{*}{ IRAQ $_{\text {dummy }}$} & 51.81 & 25.19 & 18.17 & 114.99 & 73.19 \\
\hline & $(0.000)$ & $(0.000)$ & $(\mathbf{0 . 0 0 0 )}$ & $(0.000)$ & $(0.000)$ \\
\hline \multirow{2}{*}{$\mathrm{GFC}_{\text {dummy }}$} & 0.93 & 12.75 & 0.70 & 19.20 & 1797.07 \\
\hline & $(0.336)$ & $(0.000)$ & $(0.405)$ & $(0.000)$ & $(0.000)$ \\
\hline
\end{tabular}

Note: The F-statistics is shown with numbers in parentheses are $p$-value as statistical significance. Bold $\mathrm{p}$-values denote rejection of the null hypothesis at significance levels. OP, EX, TE, CPI, IP, IRAQdummy, and $\mathrm{GFC}_{\text {dummy }}$ indicate separately oil price, exchange rate, tourist expenditure, consumer price index, industrial production, Iraq War dummy, and global financial crisis dummy. 


\section{Conclusions}

This study revisits the relationship between macro and non-macro variables and stock performance of tourist companies in Korea. We report that the ordinary least squares (OLS) regression method can make only the estimation of the mean dependent variable. The results of the OLS regression are limited when the conditional distribution is heterogeneous. Thus, we employ the quantile regression $(\mathrm{QR})$ approach to address this issue. Moreover, this study analyses the effect of financial factors on stock performance of tourism companies, and dummy variables are added in the asymptotic joint of the OLS and QR approach.

First, in the all quantiles, the significant coefficient of the exchange rate is negative and the coefficient of the CPI is positive and significant. It shows that the exchange rate and CPI are main performance determinants of stock performance of tourism companies. Second, the coefficient estimates on tourist expenditure is positive and significant at almost all quantiles while oil price is negative and significant at the medium and upper quantiles. Also, IP is negative and significant at the lower, medium, and upper quantiles. Third, there are similar characteristics of the effects between IRAQ dummy $_{\text {and }} \mathrm{GFC}_{\text {dummy }}$ on the stock performance of tourism companies. The significant coefficient of dummy variables is negative at the upper quantiles in the bullish market. The 2003 Iraq War and the 2008 global financial crisis have a unique characteristic in common that the traveler's safety, and economy can be necessary prerequisites for international travel. Results of this paper lead to consistent estimates with the research finding of Chen et al. (2005) and Li, Blake, and Cooper (2010).

The contribution is twofold. First, the exchange rate and CPI are the key factors of macro variables according to the overall results of this paper so that the stock supervisor should observe the change in trends of these macro variables carefully. In addition, the events, the Iraq War and the global financial crisis, have negative effects on the tourism stock performance. The CEO of tourism companies must make a quick decision and solution about the global crisis situation. Second, our results show that the coefficient estimates of macro and non-macro variables have not been constant throughout all quantile distributions of tourism stock using QR approach. In addition, empirical results show that the effects of macro and non-macro variables are statistically asymmetric using slope equality test at all quantiles and highly related to tourism stock performance in Korea.

Our results are also relevant from a stock performance perspective for tourism companies. Therefore, this research will be helpful to establish the strategic initiatives of an effective tourism stock performance, which the tourism companies can deal with the crisis in the stock market. Finally, this study contributes greatly to the fact that the importance of safety is directly related to tourism and also to the stock performance of the travel industry. Also, future research should include more on policy impacts as well as economic shocks and alternative stock performance measures.

\section{References}

Asprem, M. (1989). Stock prices, asset portfolios and macroeconomic variables in ten European countries. Journal of Banking and Finance, 13(4-5), 589-612. https://doi.org/10.1016/0378-4266(89)90032-0.

Broadstock, D. C., Cao, H., \& Zhang, D. (2012). Oil shocks and their impact on energy related stocks in China. Energy Economics, 34(6), 1888-1895. https://doi.org/ 10.1016/j.eneco.2012.08.008.

Chang, W. S., \& Lee, Y. H. (2017). The macroeconomic contribution to foreign-exchange earnings from tourism in Taiwan. Current Issues in Tourism, 20(11), 1110-1115. https://doi.org/10.1080/13683500.2016.1206062.

Chen, M. H., Kim, W. G. \& Kim, H. J. (2005). The impact of macroeconomic and non-macroeconomic forces on hotel stock returns. International Journal of Hospitality Management, 24(2), 243-258. https://doi.org/10.1016/ j.ijhm.2004.06.008.

Chen, M. H. (2007). Macro and non-macro explanatory factors of Chinese hotel stock returns. Hospitality Management, 26(4), 991-1004. https://doi.org/10.1016/ j.ijhm.2006.04.002.

Chen, M. H., \& Kim, H. J. (2010). Tourism expansion and corporate earnings in the tourism industry. Service Industries Journal, 30(6), 947-964. https://doi.org/ 10.1080/02642060802342646.

Cheng, X., \& Jiang, K. (2017). Study on the Influencing Factors of TFP of Low-carbon Tourism Distribution. International Journal of Industrial Distribution \& Business, 8(7), 13-20. http://dx.doi.org/10.13106/ ijidb.2017.vol8.no7.13.

Cunado, J., \& Perez de Gracia, F. (2005). Oil prices, economic activity and inflation: Evidence for some Asian countries. Quarterly Review of Economics and Finance, 45(1), 65-83. https://doi.org/10.1016/j.qref.2004.02.003.

Demir, E., Alici, Z. A., \& Lau, M. C. K. (2017). Macro explanatory factors of Turkish tourism companies' stock returns. Asia Pacific Journal of Tourism Research, 22(4), 370380. https://doi.org/10.1080/10941665.2016.12718 14.

Dragouni, M., Filis, G., Gavriilidis, K., \& Santamaria, D. (2016). Sentiment, mood and outbound tourism demand. Annals of Tourism Research, 60(1), 80-96. https://doi.org/10.1016/j.annals.2016.06.004.

Errunza, V., \& Hogan, K. (1998). Macroeconomic determinants of European stock market volatility. European Financial Management, 4(3), 361-377. https://doi.org/10.1111/1468036X.00071.

Hamilton, J. (2011). Nonlinearities and the macroeconomic effects of oil prices. Macroeconmic Dynamics, 15(3), 364-378. https://doi.org/10.1017/S1365100511000307. 
Koenker, R., \& Bassett, G. (1978). Regression quantiles. Econometrica, 46(1), 33-50. https://doi.org/10.2307/ 1913643.

Koenker, R., \& Bassett, G. (1982). Robust tests for heteroscedasticity based on regression quantiles. Econometrica, 50(1), 43-62. https://doi.org/10.2307/ 1912528.

Lee, J. W., \& Kwag, M. (2013). Green growth and sustainability: The role of tourism, travel and hospitality service industry in Korea. Journal of Distribution Science, 11(7), 15-22. http://dx.doi.org/10.13106/jds. 2013.vol11. no7.15.

Lee, J. W. \& Syah, A. M. (2018). Economic and environmental impacts of mass tourism on regional tourism destinations in Indonesia. Journal of Asian Finance, Economics and Business, 5(3), 31-41. http://doi.org/10.13106/jafeb.2018.vol5.no3.31.

Li, S., Blake, A., \& Cooper, C. (2010). China's tourism in a global financial crisis: A computable general equilibrium approach. Current Issues in Tourism, 13(5), 435-453. https://doi.org/10.1080/13683500.2010.491899.

Li, K., Jin, M., \& Shi, W. (2018). Tourism as an important impetus to promoting economic growth: A critical review. Tourism Management Perspectives, 26(1), 135-142. https://doi.org/10.1016/j.tmp.2017.10.002.

Liang, C. C., Lin, J. B., \& Hsu, H. C. (2013). Reexamining the relationships between stock prices and exchange rates in ASEAN-5 using panel Granger causality approach. Economic Modelling, 32(1), 560-563. https://doi.org/10. 1016/j.econmod.2013.03.001.

Liu, A., \& Pratt, S. (2017). Tourism's vulnerability and resilience to terrorism. Tourism Management, 60(1), 404-417. https://doi.org/10.1016/j.tourman.2017.01.001.

Lo, A., \& Lam, T. (2004). Long-haul and short-haul outbound allinclusive package tours. Asia Pacific Journal of Tourism Research, 9(2), 161-176. https://doi.org/10.1080/1094166042000233694.

Lv, Z., \& Xu, T. (2017). A panel data quantile regression analysis of the impact of corruption on tourism. Current Issues in Tourism, 20(6), 603-616. https://doi.org/10. 1080/13683500.2016.1209164.

Marrocu, E., Paci, R., \& Zara, A. (2015). Micro-economic determinants of tourist expenditure: a quantile regression approach. Tourism Management, 50(1), 13-30. https://doi.org/10.1016/j.tourman.2015.01.006.

Nandha, M., \& Faff, R. (2008). Does oil move equity prices? A global view. Energy Economics, 30(3), 986-997. https://doi.org/10.1016/j.eneco.2007.09.003.

Nusair, S. A., \& Olson, D. (2019). The effects of oil price shocks on Asian exchange rates: Evidence from quantile regression analysis. Energy Economics, 78(1), 44-63. https://doi.org/10.1016/j.eneco.2018.11.009.

Park, H., \& Park, S. (2019). The effect of emotional image on customer attitude. Journal of Asian Finance, Economics and Business, 6(3), 259-268.

https://doi.org/10.13106/ jafeb.2019.vol6.no3.259.

Poon, S., \& Taylor, S. J. (1991). Macroeconomic factors and the UK stock market. Journal of Business Finance \& Accounting, 18(5), 619-636. https://doi.org/10.1111/ j.1468-5957.1991.tb00229.x.

Rittichainuwat, B. N., \& Chakraborty, G. (2009). Perceived travel risks regarding terrorism and disease: The case of Thailand. Tourism Management, 30(3), 410-418. https://doi.org/10.1016/ j.tourman.2008.08.001.

Singal, M. (2012). Effect of consumer sentiment on hospitality expenditures and stock China returns. International Journal of Hospitality Management, 31(2), 511-521. https://doi.org/10.1016/j.ijhm.2011.07.009.

Tsai, I. C. (2012). The relationship between stock price index and exchange rate in Asian markets: A quantile regression approach. Journal of International Financial Markets, Institutions and Money, 22(3), 609-621. http://dx.doi.org/10.1016/j.intfin.2012.04.005.

Wong, H. T. (2017). Real exchange rate returns and real stock price returns. International Review of Economics and Finance, 49(1), 340-352. http://dx.doi.org/10.1016/ j.iref.2017.02.004.

Wong, K. K. F., \& Song, H. (2006). Do macroeconomic variables contain any useful information for predicting changes in hospitality stock indices? Journal of Hospitality and Tourism Research, 30(1), 16-33. https://doi.org/10.1177/1096348005284267.

Yespayev, S. S. (2014). Priorities, mechanisms and prospects on industrial clusters and special economic zones in Kazakhstan. Journal of Asian Finance, Economics and Business, 1(2), 1524. https://doi.org/10.13106/jafeb. 2014.vol1.no2.15.

You, W., Guo, Y., Zhu, H., \& Tang, Y. (2017). Oil Price shocks, economic policy uncertainty and industry stock returns in China: Asymmetric effects with quantile regression. Energy Economics, 68(1), 1-18. https://doi.org/10.1016/j.eneco.2017.09.007.

Yu, W., Lee, J.-H., \& Kim, H.-K. (2014). The influence of SNS characteristics on tourist attractions preference: Focus on China. Journal of Distribution Science, 12(9), 53-63. http://dx.doi.org/10.15722/jds.12.9.201409.53.

Zhang, J., \& Lee, H.-Y. (2016). The Word-of-Mouth Effects on the Chinese Customers' Choice Intention of Medical Tourism Destination. Journal of Distribution Science, 14(7), 21-31. http://dx.doi.org/10.15722/jds.14.7. 201607.21 